\title{
Circulatory Support as a Bridge in Pediatric Heart Transplantation in Virtue of Dilated Cardiomyopathy after Appendectomy
}

\author{
Karina Aparecida Antonelli da Silva, Cristiane Célia Pereira and Valdir Assis dos Reis Filho* \\ Instituto Dante Pazzanese de Cardiologia, São Paulo, SP, Brazil \\ *Corresponding author: Valdir Assis dos Reis Filho, Instituto Dante Pazzanese de Cardiologia, São Paulo, SP, Brazil; E-mail: valdir_assisf@hotmail.com
}

Received: November 12, 2020; Accepted: November 25, 2020; Published: December 03, 2020

\begin{abstract}
Extracorporeal membrane oxygenator (ECMO) is utilized in the recovery of patients with cardiogenic shock, as temporary hemodynamic support for the purpose of myocardial recovery or to bridge the patient to cardiac transplantation. A 13 years old man, after appendectomy, with a complaint of facial edema, reduction in the volume of diuresis, hypotension and reduction of appetite, diagnosed with dilated cardiomyopathy, biventricular systolic dysfunction and extensive myocardial fibrosis, requiring the use of mechanical circulatory support. The patient was transplanted after 31th day of ECMO support and 116th day hospitalized was discharged. This study elucidated the importance of ECMO in the management of critically patients that progress to heart failure.
\end{abstract}

\section{Introduction}

Extracorporeal membrane oxygenation (ECMO) first successfully utilized in 1975 by Robert Bartlett, therefore, its use has become popular in adults, neonates and pediatrics patients. Used for therapy in cases of heart and/or pulmonary failure, to promote myocardial recovery, it is also used as a bridge for transplantation and implantation of long-term ventricular assist devices [1,2]. Venovenous (VV) configuration is the modality of choice in cases of respiratory failure and venoarterial (VA) is utilized in cardiorespiratory arrest or cardiogenic shock. Cannulation in patients undergoing ECMO support should be individualized, the central cannulation site can be used in patients post-cardiotomy and percutaneous femoral cannulation is the most used to patients on intensive care unit (ICU), however, percutaneous cannulation is associated with vascular involvement of the lower extremity $[1,3,4]$.

ECMO circuit consists in a centrifugal pump, membrane oxygenator and heat exchanger, allowing keeping the patient in normothermia. The circuit induces the acute kidney injury and in these cases, it is possible to insert a hemoconcentrator to remove fluid, reduce interstitial edema and can raising the hematocrit level [3].

\section{Case Report}

A 13 years old man, $150 \mathrm{~cm}, 34 \mathrm{~kg}$, after appendectomy, was seen in the emergency room with a complaint of facial edema, reduction in the volume of diuresis, tingling in the lower limbs, pallor, complaining of weakness, hypotension and reduction of appetite. Arterial pressure $80 \times 50 \mathrm{mmHg}$, heart rate $80 \mathrm{bpm}$, sinus rhythm, using carvedilol, enalapril, aldactone, acetylsalicylic acid and ferrous sulphate. Patient was submitted to chest X-ray, transthoracic echocardiogram Table 1 and magnetic resonance imaging Table 2, has been shown enlargement cardiac area, the right cardiac chambers was slightly dilated and
Table 1: Transthoracic Echocardiogram after patient admission.

\begin{tabular}{|c|c|c|}
\hline Parameter rating & Value & Reference value \\
\hline Aorta $(\mathrm{mm})$ & $23 \mathrm{~mm}$ & $17-23 \mathrm{~mm}$ \\
\hline Left atrium $(\mathrm{mm})$ & $48 \mathrm{~mm}$ & $19-28 \mathrm{~mm}$ \\
\hline Right atrium $(\mathrm{mm})$ & $23 \mathrm{~mm}$ & $07-26 \mathrm{~mm}$ \\
\hline LV in diastole $(\mathrm{mm})$ & $70 \mathrm{~mm}$ & $32-45 \mathrm{~mm}$ \\
\hline LV in systole $(\mathrm{mm})$ & $62 \mathrm{~mm}$ & - \\
\hline Interventricular septum $(\mathrm{mm})$ & $05 \mathrm{~mm}$ & $06-07 \mathrm{~mm}$ \\
\hline Posterior wall $(\mathrm{mm})$ & $05 \mathrm{~mm}$ & $06-07 \mathrm{~mm}$ \\
\hline Ejection fraction $(\%)$ & $24 \%$ & $60 \%$ \\
\hline
\end{tabular}

Table 2: Magnetic resonance imaging with paramagnetic contrast injection after patient admission

\begin{tabular}{|c|c|c|}
\hline Parameter rating & Value & Reference value \\
\hline Left atrial volume $(\mathrm{mL})$ & $90 \mathrm{~mL}$ & $44-102 \mathrm{~mL}$ \\
\hline Volumetric index left atrium $\left(\mathrm{mL} / \mathrm{m}^{2}\right)$ & $76 \mathrm{~mL} / \mathrm{m}^{2}$ & $26-53 \mathrm{~mL} / \mathrm{m}^{2}$ \\
\hline Right atrium volume $(\mathrm{mL})$ & $51 \mathrm{~mL}$ & $44-102 \mathrm{~mL}$ \\
\hline Volumetric index right atrium $\left(\mathrm{mL} / \mathrm{m}^{2}\right)$ & $43 \mathrm{~mL} / \mathrm{m}^{2}$ & $43 \mathrm{~mL} / \mathrm{m}^{2}$ \\
\hline Anteroseptal wall thickness $(\mathrm{mm})$ & $04 \mathrm{~mm}$ & $7-12 \mathrm{~mm}$ \\
\hline Lower lateral wall thickness $(\mathrm{mm})$ & $03 \mathrm{~mm}$ & $7-12 \mathrm{~mm}$ \\
\hline End- diastolic diameter $(\mathrm{mm})$ & $67 \mathrm{~mm}$ & $37-55 \mathrm{~mm}$ \\
\hline End-systolic diameter (mm) & $60 \mathrm{~mm}$ & - \\
\hline End-diastolic volume (mL) & $210 \mathrm{~mL}$ & - \\
\hline Ejection fraction LV (\%) & $24 \%$ & $50-70 \%$ \\
\hline End-diastolic volume index $\left(\mathrm{mL} / \mathrm{m}^{2}\right)$ & $176 \mathrm{~mL} / \mathrm{m}^{2}$ & $53-97 \mathrm{~mL} / \mathrm{m}^{2}$ \\
\hline End-systolic volume index $\left(\mathrm{mL} / \mathrm{m}^{2}\right)$ & $134 \mathrm{~mL} / \mathrm{m}^{2}$ & $10-34 \mathrm{~mL} / \mathrm{m}^{2}$ \\
\hline Left ventricular mass $(\mathrm{g})$ & $58 \mathrm{~g}$ & - \\
\hline Right ventricular long axis (mm) & $79 \mathrm{~mm}$ & $65-95 \mathrm{~mm}$ \\
\hline right ventricular short axis $(\mathrm{mm})$ & $39 \mathrm{~mm}$ & $22-44 \mathrm{~mm}$ \\
\hline End-diastolic volume (mL) & $58 \mathrm{~mL}$ & - \\
\hline End-systolic volume (mL) & $40 \mathrm{~mL}$ & - \\
\hline RV Ejection fraction (\%) & $30 \%$ & $40-60 \%$ \\
\hline End-diastolic volume index $\left(\mathrm{mL} / \mathrm{m}^{2}\right)$ & $49 \mathrm{~mL} / \mathrm{m}^{2}$ & $67-111 \mathrm{ml} / \mathrm{m}^{2}$ \\
\hline End-systolic volume index $\left(\mathrm{mL} / \mathrm{m}^{2}\right)$ & $34 \mathrm{~mL} / \mathrm{m}^{2}$ & $20-48 \mathrm{~mL} / \mathrm{m}^{2}$ \\
\hline
\end{tabular}


chambers demonstrated important dilatation, having diffuse left ventricular hypokinesis, mitral regurgitation. Dilated right and left pulmonary artery, enlarged pulmonary trunk diameter, biventricular systolic dysfunction, pulmonary hypertension, mild pericardial effusion and with areas of late enhancement of diffuse mesocardial non-coronary pattern, suggestive of extensive myocardial fibrosis. The diagnosis was inflammatory cardiomyopathy; however, the hypothesis giant cell myocarditis has not discarded.

Presented low cardiac output and right heart failure, the patient was referred to the pediatric ICU for hemodynamic stabilization, was necessary dobutamine infusion, furosemide administration and hydration with $0.9 \%$ sodium chloride. There was clinical worsening with reduced left ventricular ejection fraction (EF Simpson de 23\% to 17\%), decreased kidney function, elevation of C-reactive protein, congestive liver dysfunction, drop in oxygen saturation, nausea and vomiting. For presenting difficulty in hemodynamic management, it was necessary to increase the dose of dobutamine and started the primacor infusion, the patient was subsequently included on heart transplant waiting list. He presented severe metabolic acidosis, adrenaline $0.15 \mathrm{mcg} / \mathrm{Kg} / \mathrm{min}$ was staterd, the intubated patient receiving mechanical ventilation and opted for the installation of ECMO circulatory support.

ECMO circuit with 3/8 diameter tubes, centrifugal pump (Rotaflow Centrifugal Pump ${ }^{\circ}$ ) and polymethylpentene oxygenator membrane (Quadrox-ID Adult - Bioline Coated - MAQUET Cardiopulmonary AG) was installed. The circuit was primed with $0.9 \%$ sodium chloride and red cell concentrate. Cannulation was performed with dissection of the right femoral artery and vein, an arterial cannula number 16 and an intravenous number 22 were introduced. A temporary intravascular shunt was placed for distal reperfusion of the femoral artery, to maintain the viability of the limb.

The heparinization was performed at a dose of $50 \mathrm{IU} / \mathrm{kg}$ bolus, thereafter heparin was infused continuously at a rate of $10 \mathrm{IU} / \mathrm{kg} / \mathrm{h}$, adjusted according to the activated coagulation time (ACT) (MCA $2000 \mathrm{FAJ}^{\circ}$ ) and activated partial thromboplastin time (aPTT). Circulatory support was initiation with the flow $80 \mathrm{ml} / \mathrm{kg} / \mathrm{min}$, gas flow of 0.9 and $\mathrm{FiO}^{2}$ at $50 \%$. 06 hours later after installation, it was possible to observe improvement in the patient's hemodynamics, with return of diuresis, reduction of vasoactive drugs infusion and improvement in peripheral circulation Table 3.

12 hours later of ECMO installation, it decided a treatment of dialysate solution which circulates past the hemodiafiltration membrane, with the purpose of promoting the improvement of renal function and reducing interstitial edema. The technique was performed throughout the period in circulatory Support. The hemodialfiltration is a safe and effective technique based on hemodialysis, performed by the hemoconcentrator applied to the ECMO circuit. It is common for patients in ECMO to develop renal failure due to volume overload, and an alternative to minimize this condition is the use of continuous renal replacement therapy (CRRT), however, the disadvantages of this method are related to the pressure alarm in the entry and exit routes of the CRRT, which can interrupt the procedure and cause hemolysis and microembolism. An alternative to the use of CRRT is continuous hemofiltration that is easy to perform on the ECMO circuit [5].
Table 3: Clinical and hemodynamic parameters before and after implantation of the ECMO.

\begin{tabular}{|c|c|c|c|}
\hline Parameters & Before ECMO & After 6 h & After 12 h \\
\hline Arterial pressure & $85 \times 58 \mathrm{mmHg}$ & $102 \times 90 \mathrm{mmHg}$ & $80 \times 78 \mathrm{mmHg}$ \\
\hline Heart rate & $110 \mathrm{bpm}$ & $109 \mathrm{bpm}$ & $108 \mathrm{bpm}$ \\
\hline Lactate & 14,7 & 6,0 & 2,8 \\
\hline Bicarbonate & 16,2 & 27,8 & 29,7 \\
\hline $\mathrm{pH}$ & $\begin{array}{c}\text { Severe metabolic } \\
\text { acidosis }\end{array}$ & 7,38 & 7,49 \\
\hline Diuresis & $200 \mathrm{~mL}$ & $870 \mathrm{~mL}$ & $2025 \mathrm{~mL}$ \\
\hline Vasoactie drugs & $\begin{array}{c}\text { Dobutamine } 10 \\
\mathrm{mcg} / \mathrm{Kg} / \mathrm{min} \\
\text { Milrinone } 0,5 \mathrm{mcg} / \\
\mathrm{Kg} / \mathrm{min} \\
\mathrm{Adrenalin} 0,15 \\
\mathrm{mcg} / \mathrm{Kg} / \mathrm{min}\end{array}$ & $\begin{array}{c}\text { Milrinone } 0,5 \mathrm{mcg} / \\
\mathrm{Kg} / \mathrm{min} \\
\text { Adrenalin } 0,15 \mathrm{mcg} / \\
\mathrm{Kg} / \mathrm{min}\end{array}$ & $\begin{array}{c}\text { Milrinone } 0,5 \mathrm{mcg} / \\
\mathrm{Kg} / \mathrm{min} \\
\mathrm{Adrenalin} 0,15 \\
\mathrm{mcg} / \mathrm{Kg} / \mathrm{min}\end{array}$ \\
\hline
\end{tabular}

The patient evolved with difficulty in ventilation with unsatisfactory tidal volume. After chest X-ray examination, an important left pleural effusion was detected, which subsequently led to an improvement in pulmonary auscultation and effusion. 48 hours after ECMO installation, left ventricular decompression was realized due to a pinkish frothy discharge was found in the endotracheal tube, suggestive of acute pulmonary edema. An atrial septostomy was performed with a $9.6 \mathrm{~mm}$ balloon with a mean gradient of $2 \mathrm{mmHg}$. Compression of left ventricular chamber occurs due to the retrograde flow of arterial cannula, increasing afterload on left ventricular, which can result in an increase in LV end diastolic pressure and pulmonary capillary pressure, consequently in a complication of pulmonary congestion presented by the patient [4]. The patient received a transfusion of irradiated red blood cells, maintaining a hemoglobin level above $10 \mathrm{~g} / \mathrm{dL}$, in addition to platelet concentrate, fresh frozen plasma and cryoprecipitate during all circulatory support. Nutrition was of the hypercaloric parenteral without lipid emulsion. Patient was sedated with midazolam, ketamine and morphine, presenting isochoric and photoreactive pupils.

The management of ECMO was performed according to the institutional protocol ICU. Two circuit changes were necessary, the first occurred on the 9th day of ECMO and on the 17th day, due to the presence of fibrin in the post-membrane of oxygenator, the anticoagulation was into parameters (TTpa 86 to 105 seconds; TTpa ratio 2.5 to 3; TCA $180-220$ seconds). On the 31th day of ECMO support, the patient was offered the organ and underwent a heart transplant. The donor was man, 39 years old and $70 \mathrm{~kg}$, declared death by hemorrhagic stroke. Receptor underwent a thoracotomy, with pericardiectomy, followed by cannulation of ascending aorta, inferior and superior vena cava. Subsequently, patient was submitted the cardiopulmonary bypass (CPB) and removed from circulatory support. The cardiopulmonary bypass time was 120 minutes, anoxia time 135 minutes and the implant 55 minutes. Flow in CPB was maintained between $80-100 \mathrm{~mL} / \mathrm{Kg} / \mathrm{min}$, the patient was maintained in moderate hypothermia $32^{\circ} \mathrm{C}$. After aortic unclamping, was observed the spontaneous return of cardiac function with recovery in sinus rhythm Table 4.

After cardiac transplantation, the patient was referred to the ICU with dose of dobutamine $(3 \mathrm{mcg} / \mathrm{Kg} / \mathrm{min})$, primacor $(0.5 \mathrm{mcg} /$ 


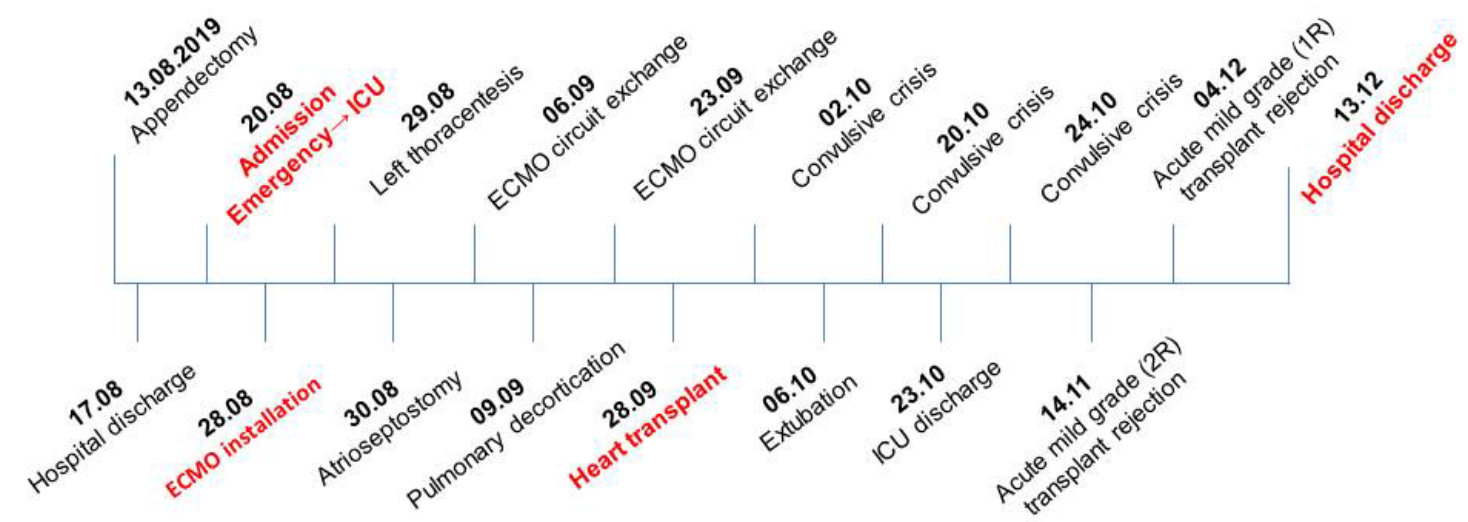

Figure 1: Timeline clinical events of the patient.

Table 4: Patient blood gas analysis in ECMO support, $\mathrm{CPB}$ at $37^{\circ} \mathrm{C}$ and post-CPB.

\begin{tabular}{|c|c|c|c|}
\hline Blood gas analysis & ECMO & CPB $\left(37^{\circ} \mathbf{C}\right)$ & Post - CPB \\
\hline $\mathrm{pH}$ & 7,51 & 7,34 & 7,42 \\
\hline $\mathrm{PCO}_{2}$ & 33 & 40 & 41 \\
\hline $\mathrm{PO}_{2}$ & 197 & 275 & 106 \\
\hline $\mathrm{SatO}_{2}$ & 99,7 & 100 & 98,8 \\
\hline $\mathrm{BE}$ & 3,3 & $-3,9$ & 2,4 \\
\hline $\mathrm{CO}_{2}$ & 27,9 & 22,8 & 28,5 \\
\hline $\mathrm{HCO}_{3}$ & 26,8 & 21,6 & 27,2 \\
\hline Cálcio & 1,20 & 1,50 & 1,27 \\
\hline Lactate & 1,1 & 3,3 & 2,8 \\
\hline Glucose & 115 & 166 & 158 \\
\hline Hematocrit & $32 \%$ & $29 \%$ & $29 \%$ \\
\hline Hemoglobin & 10,8 & 9,8 & 9,5 \\
\hline Sodium & 134 & 135 & 138 \\
\hline Potassium & 3,7 & 4,8 & 3,5 \\
\hline
\end{tabular}

$\mathrm{Kg} / \mathrm{min}$ ) and nitroprusside $(1.8 \mathrm{mcg} / \mathrm{Kg} / \mathrm{min})$, and the beginning of methylprednisolone. Echocardiography showed $69 \%$ ejection fraction, with HR of $117 \mathrm{bpm}$ and MAP of 136 x $69 \mathrm{mmHg}$. Renal function was adequate $(160 \mathrm{~mL} / \mathrm{hr})$, with serum urea and creatinine at normal levels. On the 3rd postoperative day, the patient was referred to the pediatric ward, however, presented 3 episodes of seizures. A computed tomography scan of the skull was performed, which showed ischemia in the occipital, bilateral temporal and right frontal regions, these are an old injury. These were the only episodes, without sequelae, and levetiracetam was prescribed.

After 116th days hospitalized, the patient was discharged, with a final diagnosis of acute mild grade (1R) transplant rejection and continuous treatment of prednisolone, Prophylactic bactrim, everolimus, enalapril, folic acid, amlodipine and levetiracetam, nystatin, omeprazole, dipyrone and tramal if necessary. Figure 1 shows the timeline of the patient's clinical course.

\section{Discussion}

Technological advances and improvement of technique, the ECMO became safer and more effective, not being used only in post cardiotomy cardiogenic shock, but also being used in multifactorial cardiogenic shock and/or in cardiorespiratory arrest, being possible to increase the survival time of patient. Complications in ECMO can be mechanical, occurring in the circuit (pump, membrane oxygenator, PVC tubes and cannulation), or clinical, dependent on the patient's physiological response. The longer time on circulatory support, the greater the incidence of complications, when its management is careful and based on an institucional protocol, complications almost always not affect the final result, favoring the patient's recovery and justifying the cost-benefit, as seen in this case report. The study ratified the importance and cost-benefit of ECMO in the management of patients in serious condition and who progress with heart failure. This support promotes individual hemodynamic stability, which allows a longer waiting time for transplantation. It's the important of multidisciplinary work in matters of pharmacology, physiotherapy and nutrition, in addition to the adequate clinical management of the patient and ECMO, aiming the patient's discharge without comorbidities.

\section{References}

1. Durães AR, Figueira FAMS, Lafayette AR, Juliana de Castro Solano Martins, Sá Juliano Cavalcante de (2015) Use of venoarterial extracorporeal membrane oxygenation in fulminant chagasic myocarditis as a bridge to heart transplant. Rev Bras Ter Intensiva 27: 397-401. [crossref]

2. Díaz R, Fajardo C, Rufs J (2017) Historia Del ECMO (Oxigenación por membrana extracorpórea o soporte vital extracorpóreo). Rev Med Clin Condes 28: 796-802.

3. Silva MP, Caeiro D, Fernandes P, Cláudio Guerreiro, Eduardo Vilela, et al. (2017) Oxigenação por membrana extracorporal na falência circulatória e respiratória experiência de um centro. Rev Port Cardiol 36: 833-842. [crossref]

4. Guglin M, Zucker MJ, Bazan VM, Biykem Bozkurt, Aly El Banayosy, et al. (2019) Venoarterial ECMO for Adults: JACC Scientific Expert Panel. J Am Coll Cardiol 73: 698-716. [crossref]

5. Cyrino FOS (2019) Relato de caso: Hemofiltração venovenosa contínua associada ao líquido de hemodiálise durante a ECMO - Benefícios metabólicos e balanço hídrico. In: Congresso da Sociedade Brasileira de Cirurgia Cardiovascular, 2019, Belo Horizonte. Brazilian Journal of Cardiovascular Surgery 2-89.

\section{Citation:}

Antonelli da Silva KA, Célia Pereira C, dos Reis Filho VA (2020) Circulatory Support as a Bridge in Pediatric Heart Transplantation in Virtue of Dilated Cardiomyopathy after Appendectomy. J Cardiol Clin Pract Volume 3(3): 1-3. 